\title{
Taraka Mantra for Successful Breastfeeding: More Suckling- More Milk
}

\section{Manjubala Dash*}

Professor in Nursing, National Trainer for Infant Feeding, MTPG \& RIHS, Puducherry, India

*Corresponding Author: Manjubala Dash, Professor in Nursing, National Trainer for Infant Feeding, MTPG \& RIHS, Puducherry, India.

Received: August 06, 2019; Published: August 13, 2019

August First Week every year celebrated as World Breastfeeding Week. So various Programmes are conducted in all Institutions, Hospitals and Villages to create awareness among the Public and Mothers, but still there is Gap.... Lets Discuss---Why and How to Overcome---- Breast feeding is the best food for the new born. It's the Birth Rights of the Baby. It's a traditional Practice. Today we notice the Exclusive breastfeeding rates are not $100 \%$ though there is 100\% Institutional Deliveries especially in Pondicherry.

Knowledge on Advantages of Breastfeeding is exist among the general Public and also each mother knows breastfeeding is the only best milk for their baby but still there is a Gap.

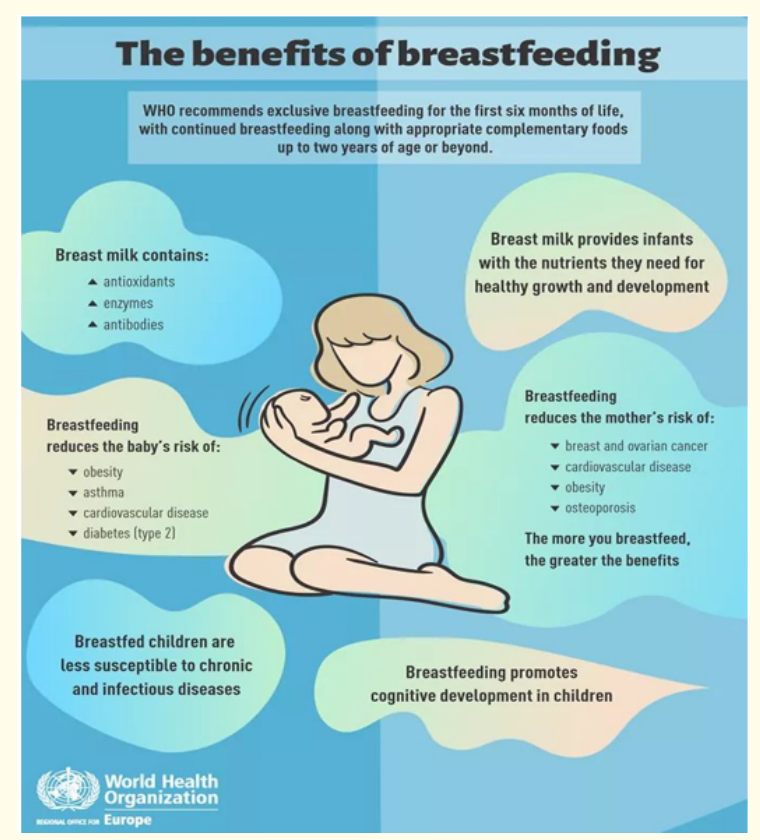

Figure 1

Let's Discuss the advantages of Breastfeeding to the Baby, Mother and to Society- As per WHO Breast milk is

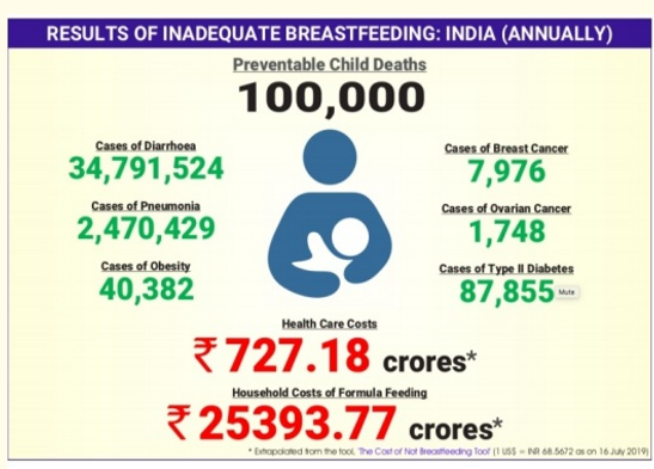

Figure 2

Baby

- Perfect nutrients

- Easily digestible

- Ready to serve

- Protects against infection

- Protects against adult onset diseases (diabetes, high blood pressure

- Helps bonding and development

- Helps in adequate growth and development

- Enhances brain and visual development

- Baby has higher intelligence quotient

- Prevents hypothermia

Mother

- Reduces post delivery bleeding and anemia

- Delays next pregnancy

- Protects breast and ovarian cancer

- Protects obesity and shapes body

- Convenient

Family

- $\quad$ Economic benefits

- Less illnesses

- $\quad$ Family bonding 
Society

- Eco-friendly

- Human resource development

- Economy development

Recent data of India highlights we can prevent 100,000 child death per Year. There are 34,729,524 children suffering from Diarrhea, around 2,470,429 cases of Pneumonia, 40,382 cases of Obesity per year are the consequence of artificial feeding, which could be avoided if exclusive breastfeeding to be given to each baby.

Further the data also alert all of us as citizen of India to save the National Economy as well as family cost could be avoided. when we give artificial milk to the baby then it not only leads to various diseases but also affect the family economical status and due this financial crisis the mothers give diluted milk which lack adequate nutrition leads to Malnutrition, stunted growth and wasted growth among children.

The first 1000 days of life is very crucial period as the maximum growth and development takes place and it leads to irreversible change among the children leads to generation gap. So it is very important to sensitize every men and women regarding the cost of life of their own child.

Why there is Gap- Why Mother Don't Feed their Child? Reasons

- The Most common complaint- Mother perceive that they don't have enough milk for feed the baby

- $\quad$ Find difficulties to feed during nights- sleep disturbances

- Need to go for job

- No family support

- Breast conditions-like small size, small nipple, inverted nipple etc interferes and leads to lack of confidence among the mothers.

What is the true fact and how to help mothers for successful breastfeeding

- Each mother must know breast size does not have any effect to milk production as each breast either small or big size contains millions of milk secreting cells and all mothers have Oxytocin and Prolactin hormone which is responsible for milk secretion and let down. the hormones are better secreted when the baby suckle to the breast. Effective suckling leads to effecting feeding. So one Taraka Mantra for successful feeding is More Suckling- More Milk. This should be a message to be given to each mother.
- As prolactin will be produced more during early morning mostly between 3 to 4 am so Night feeding to be encouraged for continuing milk supply/production- this will help the mothers to away from the feeling of not enough milk.

- Further nipple conditions like small nipple, flat nipple and inverted nipple has no role in breastfeeding as the areola not to the nipple. For areola suckling the baby need to have mouthful of breast. This is another important point all mother must know before e discharge from Hospital.

- To build confidence each mother must know regarding growth pattern of the baby. They need to know that baby should pass urine 6 to 8 times per day and minimum 500 to $1 \mathrm{~kg}$ weight gain per month. This two signs are the reliable sign that their baby is getting enough milk.

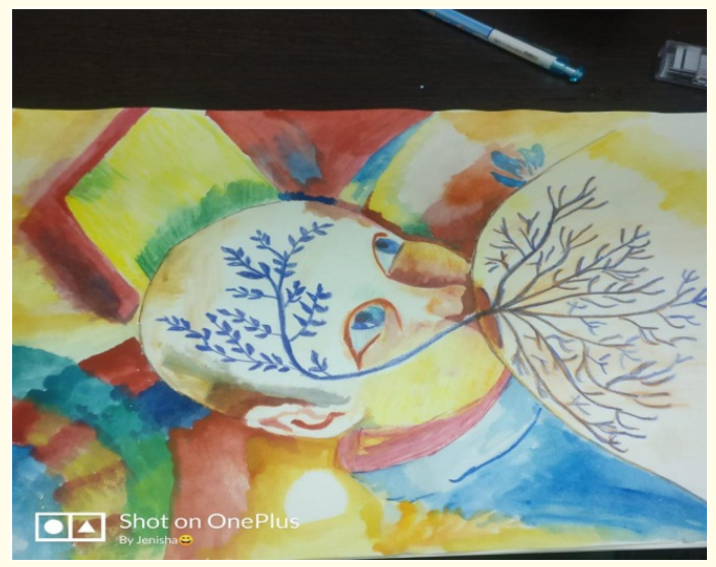

Figure 3

Key message

- Mother should be prepared from the time of pregnancy for breastfeeding.

- One to one education to be imparted to all mothers regarding breastfeeding, issues and management so they will have confidence to handle any situation.

- breastfeeding should be initiated within one hour (as early as possible) soon after delivery, either Normal delivery or CSection as the newborn is very alert in this first 1 hour.

- Each mother should be assisted by a trained lactation counselor during postnatal period while they are in Hospital

- $\quad$ Each mother need to learn good attachment and positioning - is the basics of breastfeeding. Baby should be fully supported from neck, shoulder and back, baby's body should touch to the mothers body, babies face should be towards mother's breast and baby's nose to be in mother's nipple line. This points each mother need to learn for successful feeding. So 
they need to be observed and demonstrated if needed by the lactation counselor.

- Above all very important is family support. Support from Husband and In-Laws. As the common saying by in laws- they too delivered child so they know everything and daughter in law should obey them. This is a hindering factor to be taken care by all parents.

- $\quad$ All the health care providers must undergo training on IYCF in order to help mothers.

- Govt can appoint Lactation Counsellor in all Maternity Hospitals.

So, for all the condition one solution is milk secretion. If it is there surely each mother will continue feeding and for milk secretion important is areola suckling (Mouthful of Breast), Night feeding, Frequent feeding (More Suckling -More Milk).

MTPG \& RIHS Conducting Various awareness programmes like Rally With Govt of Puducherry, Competitions among students, programmes at various PHC, CHC, quiz for SFGs', ASHAs' and mothers, Proagraame at Beach- phamphlet distribution, Mime show and villupattu, awareness talks in various Institutions etc with full support by our Institution Dean Dr. S. Jayanthi and College of Nursing Principal DR. A. Felicia Chita along with all faculty of College of Nursing, other National Trainers, Students. Prizes, Phamphlets and Snacks for these programmes supported by President and Secretary of Inner wheel club of Puducherry \& Rotary Club of Pondicherry Heritage.

\section{Acknowledgement}

Author like to acknowledge to her Guru's in the field of lactation management, Dr. S. Srinivasan, Dr. K. P.Kushwaha, Dr. K. Kesavulu, Dr. K. Raghunath and BPNI, New Delhi. ACTA PAEDIATRICS for making this concept lively and it is reached to many readers.

\section{Volume 2 Issue 9 September 2019}

(C) All rights are reserved by Manjubala Dash. 